\title{
Increased plasma concentrations of osteoprotegerin in type 2 diabetic patients with microvascular complications
}

\author{
S T Knudsen, C H Foss, P L Poulsen, N H Andersen, C E Mogensen and L M Rasmussen ${ }^{1}$ \\ Medical Department M (Diabetes \& Endocrinology) and ${ }^{1}$ Research Laboratory for Biochemical Pathology, Institute of Pathology, \\ Aarhus Kommunehospital, Aarhus University Hospital, Aarhus, Denmark
}

(Correspondence should be addressed to S T Knudsen, Medical Department M (Diabetes E Endocrinology), Aarhus Kommunehospital, DK-800O Aarhus C, Denmark; Email: stk@dadlnet.dk)

\begin{abstract}
Objective: Osteoprotegerin (OPG) is a newly identified inhibitor of bone resorption. Recent studies indicate that OPG also acts as an important regulatory molecule in the vasculature. Plasma levels of OPG seem to be elevated in subjects with diabetes as well as in non-diabetic subjects with cardiovascular disease. The aim of the present study was to examine the association between plasma OPG levels and microvascular complications and glycemic control in patients with type 2 diabetes.

Design and methods: Four groups of 20 subjects in each, individually matched for age and gender, were included in the study: (i) subjects with normal glucose tolerance (NGT); (ii) subjects with impaired glucose tolerance (IGT); (iii) type 2 diabetic patients without retinopathy; and (iv) type 2 diabetic patients with diabetic maculopathy (DMa). Plasma concentration of OPG was measured in duplicate by a sandwich ELISA method. Furthermore, fundus photography, flourescein angiography, and measurements of urinary albumin excretion rate (RIA) were performed.

Results: Plasma OPG was significantly higher in diabetic (iii + iv) than in NGT (i) subjects (3.04 \pm 0.15 vs $2.54 \pm 0.16 \mathrm{ng} / \mathrm{l}, P<0.05$ ). Plasma OPG was significantly higher in the DMa (iv) group than in the NGT (i) group $(3.25 \pm 0.23$ vs $2.54 \pm 0.16 \mathrm{ng} / \mathrm{l}, P=0.01)$. Moreover, plasma OPG was significantly higher $(3.61 \pm 0.36 \mathrm{ng} / \mathrm{l})$ in the group of diabetic subjects with both microalbuminuria and DMa $(n=7)$ than in the NGT (i) $(2.54 \pm 0.16 \mathrm{ng} / \mathrm{l}, P<0.01)$, IGT (ii) $(2.82 \pm 0.21 \mathrm{ng} / \mathrm{l}, P<0.05)$, and no retinopathy (iii) groups $(2.83 \pm 0.20 \mathrm{ng} / \mathrm{l}, \mathrm{P}<0.05)$.

Conclusions: We found increased levels of OPG in plasma from diabetic patients with microvascular complications. This finding indicates that OPG may be involved in the development of vascular dysfunction in diabetes.
\end{abstract}

European Journal of Endocrinology 149 39-42

\section{Introduction}

Osteoprotegerin (OPG) is a recently identified glycoprotein, belonging to the tumor necrosis factor receptor superfamily, originally discovered as an inhibitor of bone resorption. This inhibition is mediated through OPG's binding and neutralization of the receptor activator of nuclear factor- $\mathrm{kB}$ ligand, a strong inducer of ostoeoclast differentiation (1). OPG is present in the circulation but, despite its important roles in bone regulation, no clear association between bone mineral content or fracture risk and plasma concentrations of the molecule has been demonstrated $(2,3)$.

Recent studies have indicated that OPG also acts as an important regulatory molecule in the vasculature. Thus, OPG is present in the arterial wall (4) and, interestingly, OPG-deficient mice develop vascular calcifications of the same linear type in tunica media as are commonly seen in diabetes (5). Furthermore, in vitro studies have shown that OPG is expressed in vascular smooth muscle cells (6), and that it can act as a survival factor for endothelial cells (7). In a recent study in non-diabetic subjects a strong association between plasma levels of OPG and the presence and severity of coronary artery disease was observed (8). Moreover, in a large observational study, plasma concentrations of OPG were higher in diabetic than in non-diabetic subjects (3). However, the diabetic patients were not characterized with regard to microvascular complications, and it may therefore be hypothesized that the increased values of OPG could reflect vascular damage in this patient group. At present, no studies have examined the potential role of OPG in diabetic microvascular disease. The aim of the present study was therefore to compare plasma OPG levels in type 2 diabetic patients with and without microvascular complications, subjects with impaired glucose tolerance (IGT), as well as subjects with normal glucose tolerance 
(NGT). Furthermore, we wanted to examine the association between plasma OPG levels and glycemic control in patients with type 2 diabetes.

\section{Subjects and methods}

\section{Subjects}

Four groups of 20 subjects in each were included in the study: (i) subjects with NGT; (ii) subjects with IGT; (iii) type 2 diabetic patients without retinopathy; and (iv) type 2 diabetic patients with diabetic maculopathy (DMa) (9). The subjects from the four groups were individually matched for age and gender; moreover, the diabetic subjects were matched for known duration of diabetes. The classification of subjects as having NGT, IGT, or type 2 diabetes was based on the result of an oral glucose tolerance test, which was evaluated according to World Health Organization criteria. DMa was defined as retinal hemorrhages and/or microaneurysms combined with hard exudates and/or retinal edema in the macular area. The division of diabetic patients according to the presence or absence of DMa was based on a thorough ophthalmological examination including measurement of visual acuity, slit lamp examination, fundus photography (one $60^{\circ}$ image centered on the fovea and a nasally displaced field centered on the optic disk), as well as fluorescein angiography.

Patients were classified as having macrovascular disease if one or more of the following was present: symptoms of angina pectoris, history of myocardial infarction, coronary artery by-pass grafting or percutaneous transluminal coronary angioplasty, symptoms of or operation for intermittent claudication, amputations, or history of stroke.

The study adhered to the tenets of the Declaration of Helsinki, and it was approved by the regional ethics committee. All participants gave written informed consent to their participation.

\section{Measurements}

EDTA-plasma samples were collected after an overnight fast $(10-12 \mathrm{~h})$. The plasma concentration of OPG was measured by a commercially available kit (R\&D Systems, Minneapolis, MN, USA). The assay is a sandwich enzyme-linked immunosorbent assay, using a mouse anti-human OPG as capture antibody and a biotinylated goat anti-human OPG for detection. Recombinant human OPG was used for calibration and the range of the assay was $62.5-4000 \mathrm{pg} / \mathrm{ml}$. Plasma samples were diluted $1 / 3$ and measured in duplicate. The intra-assay coefficient of variation, as judged from duplicate measurements, was $3.5 \%$.

Hemoglobin $\mathrm{A}_{1 \mathrm{c}}\left(\mathrm{Hb}_{1 \mathrm{c}}\right)$ was determined by high performance liquid chromatography (non-diabetic range $4.4-6.4 \%$ ). Blood glucose was determined by
Reflolux II (Boehringer Mannheim, Mannheim, Germany). Urinary albumin excretion rate (UAE) was measured by radioimmunoassay and expressed as geometric mean of three overnight collections made within 1 week. Patients were classified as normoalbuminuric (at least two out of three UAEs $<20 \mu \mathrm{g} / \mathrm{min}$ ), microalbuminuric (at least two out of three UAEs between 20 and $200 \mu \mathrm{g} / \mathrm{min}$ ), or macroalbuminuric (at least two out of three UAEs $>200 \mu \mathrm{g} / \mathrm{min}$ ).

\section{Statistical analysis}

Differences between groups were tested by the Student's $t$-test (unpaired). For non-continuous variables the $\chi^{2}$ test with Yates' correction was used. Correlations were analysed using Pearson's test. A two-tailed $P$ value of less than 0.05 was considered significant. Results for normally distributed variables are expressed as means \pm S.E.; UAE values were log-transformed prior to analysis, and are expressed as geometric means $\times / \div$ tolerance factor.

\section{Results}

Clinical and laboratory characteristics of the subjects are given in Table 1. The groups were well matched with regard to gender, age, and known duration of diabetes. Values of $\mathrm{HbA}_{1 \mathrm{c}}$ and fasting blood glucose increased gradually from the NGT to the DMa group, whereas UAE was significantly elevated only in the group with DMa. Plasma OPG was higher in diabetic $(n=40)$ than in NGT subjects $(3.04 \pm 0.15$ vs $2.54 \pm 0.16 \mathrm{ng} / \mathrm{l}, \quad P<0.05)$. However, plasma OPG was significantly higher in the DMa group than in the NGT group $(3.25 \pm 0.23$ vs $2.54 \pm 0.16 \mathrm{ng} / \mathrm{l}$, $P=0.01$, whereas there were no significant differences in plasma OPG between the NGT, IGT, and no retinopathy groups (Fig. 1). Seven diabetic patients had microalbuminuria (average UAE $33.5 \times / \div$ $1.4 \mu \mathrm{g} / \mathrm{min}$ ); all of these also had DMa. In these seven subjects, displaying both microvascular complications, plasma OPG was significantly higher (3.61 $0.36 \mathrm{ng} / \mathrm{l})$ than in the NGT $(2.54 \pm 0.16 \mathrm{ng} / \mathrm{l}$, $P<0.01)$, IGT $(2.82 \pm 0.21 \mathrm{ng} / \mathrm{l}, P<0.05)$, and no retinopathy groups $(2.83 \pm 0.20 \mathrm{ng} / \mathrm{l}, \quad P<0.05)$ (Fig. 2). Diabetic patients with $(n=7)$ and without $(n=33)$ macrovascular disease had similar plasma OPG (3.1 \pm 0.58 vs $3.0 \pm 1.0 \mathrm{ng} / \mathrm{l}$, not significant).

In the total group of subjects $(n=80)$, plasma OPG correlated significantly with age $(r=0.33$, $P=0.003), \mathrm{HbA}_{1 \mathrm{c}}(r=0.36, P=0.001)$, and UAE $(r=0.27, P=0.02)$, whereas there were no correlations between plasma OPG and other clinical or laboratory parameters. In diabetic patients $(n=40)$, plasma OPG correlated significantly with age $(r=0.41, P=0.01)$ and $\mathrm{HbA}_{1 \mathrm{c}}(r=0.39, P=0.01)$, but not with UAE, macrovascular disease, or any 
Table 1 Clinical and laboratory characteristics of study participants. Data are given as number or means \pm S.E.M., except UAE which are geometric means $\times 1 \div$ tolerance factor.

\begin{tabular}{|c|c|c|c|c|}
\hline & \multicolumn{2}{|c|}{ Control groups } & \multicolumn{2}{|c|}{ Type 2 diabetes } \\
\hline & NGT & IGT & No retinopathy & Maculopathy \\
\hline Number (male/female) & $20(12 / 8)$ & $20(12 / 8)$ & $20(12 / 8)$ & $20(12 / 8)$ \\
\hline Age (years) & $61.6 \pm 1.3$ & $61.0 \pm 1.3$ & $61.9 \pm 1.4$ & $60.9 \pm 1.5$ \\
\hline Known diabetes duration (years) & NA & NA & $10.0 \pm 1.6$ & $9.2 \pm 1.6$ \\
\hline Fasting blood qlucose $(\mathrm{mmol} / \mathrm{l})$ & $4.2 \pm 0.1$ & $5.7 \pm 0.3^{\mathrm{a}}$ & $8.1 \pm 0.6^{\mathrm{b}}$ & $9.4 \pm 0.8^{b}$ \\
\hline $\mathrm{HbA}_{1 \mathrm{c}}(\%)$ & $4.8 \pm 0.07$ & $5.3 \pm 0.2$ & $7.4 \pm 0.3^{\mathrm{b}}$ & $8.5 \pm 0.3^{\mathrm{bc}}$ \\
\hline UAE rate $(\mu \mathrm{g} / \mathrm{min})$ & $3.2 \times 1 \div 1.8$ & $4.2 \times 1 \div 2.3$ & $3.9 \times 1 \div 1.9$ & $9.3 \times 1 \div 3.1^{d}$ \\
\hline Plasma OPG (ng/l) & $2.54 \pm 0.16$ & $2.82 \pm 0.21$ & $2.83 \pm 0.20$ & $3.25 \pm 0.23^{\mathrm{a}}$ \\
\hline
\end{tabular}

NA, not applicable.
${ }^{\mathrm{a}} P<0.05$ vs NGT, ${ }^{\mathrm{b}} P<0.01$ vs control groups, ${ }^{\mathrm{c}} P<0.05$ vs no retinopathy, ${ }^{\mathrm{d}} P<0.01$ vs all other groups.

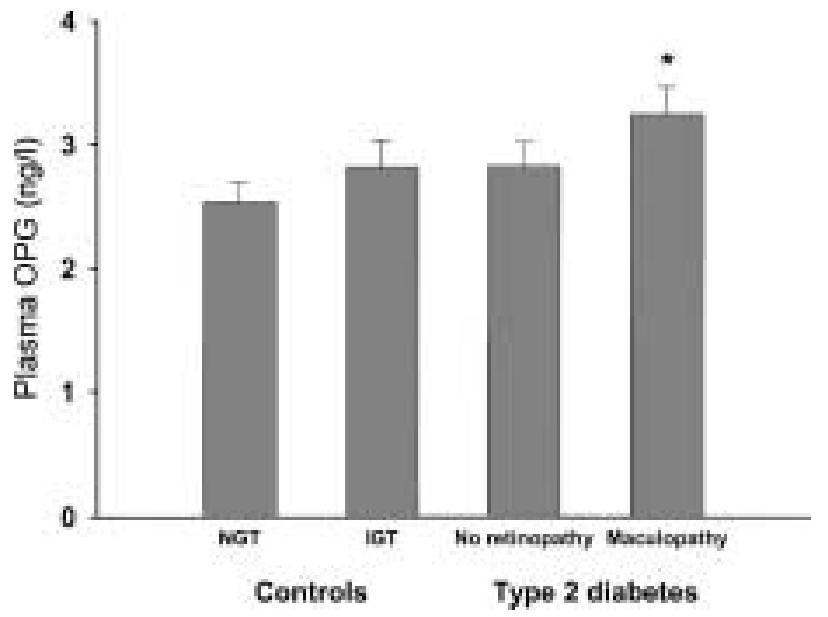

Figure 1 Plasma OPG concentrations in subjects with NGT and IGT, as well as in type 2 diabetic patients without retinopathy and with maculopathy. Data are means \pm S.E. ${ }^{*} P=0.01$ vs NGT.

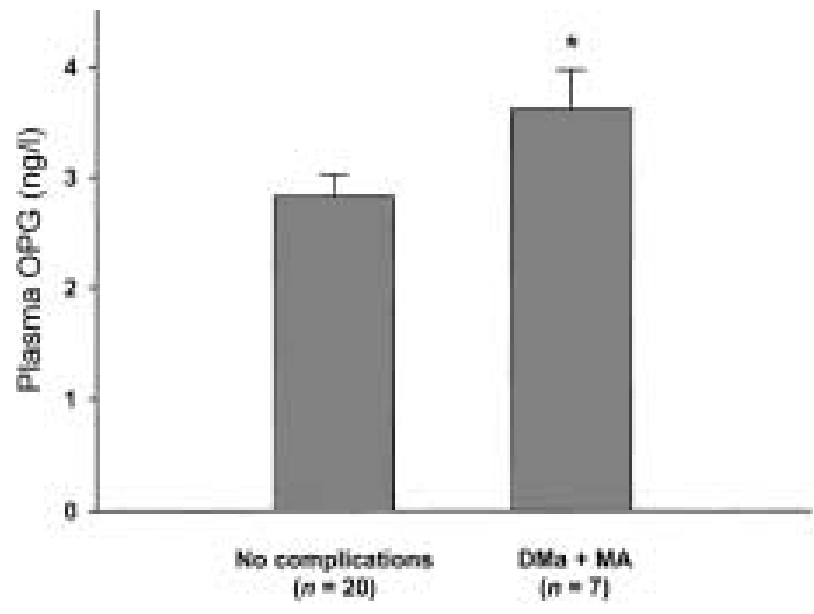

Figure 2 Plasma OPG concentrations in type 2 diabetic patients without microvascular complications or with both $\mathrm{DMa}$ and microalbuminuria (MA). Data are means \pm S.E. ${ }^{*} P<0.05$ vs no complications. other parameters. The association between plasma OPG and $\mathrm{HbA}_{1 \mathrm{c}}$ was unchanged after correction for the retinopathy group. In a multivariate analysis, including age, $\mathrm{HbA}_{1 \mathrm{c}}$, and UAE, predictors of plasma OPG in diabetic patients were age and $\mathrm{HbA}_{1 \mathrm{c}}(P=0.02$ for both, for the total analysis $r=0.53, P=0.002$ ).

\section{Discussion}

The major finding of this study was the increased plasma concentration of OPG in type 2 diabetic patients with DMa and microalbuminuria. This observation is in agreement with results from a previous study, where OPG concentrations were elevated in patients with diabetes (3). In that study, no information on the degree of micro- or macrovascular complications among the diabetic participants was provided (3). In the present study, we found that plasma values of OPG were significantly increased only in patients with microvascular complications, suggesting that elevated plasma levels of OPG may reflect microvascular damage among patients with diabetes rather than the diabetic state per se. Only two previous papers have examined the possible relation between plasma OPG and vascular dysfunction, and these studies have both focused on macrovascular disease in non-diabetic individuals. In a prospective study of almost 500 women, high OPG values were associated with an increased cardiovascular mortality (3). In another recent investigation, the authors found an association between OPG levels and the presence and severity of coronary artery disease in subjects undergoing coronary arteriography (8). In the present study, we could not demonstrate any correlation between plasma OPG and the presence of macrovascular disease. However, only a few patients in our study had symptoms or signs of macrovascular disease, and as our main focus was on microvascular disease, no invasive tests for macrovascular disease were performed.

Several studies support a role of OPG in vascular homeostasis. Thus, OPG is abundantly expressed in the media of large arteries (1), in atherosclerotic 
plaques (4), as well as in vascular smooth muscle cells (6). Furthermore, OPG has been demonstrated to act as a survival factor for endothelial cells (7), and mice lacking the ability to produce OPG develop vascular calcifications of the same type as commonly seen in diabetes (5). Thus, OPG may act as a vascular protective factor, possibly by inhibiting vascular calcification, and yet plasma OPG levels appear to be elevated in subjects with vascular damage $(3,8)$. Hofbauer \& Schoppet (10) have discussed these consistent but seemingly conflicting OPG data. They propose that increased OPG levels may represent an (incomplete) defense mechanism against other factors that promote arterial calcification, atherosclerosis, and other forms of vascular damage.

OPG is produced by a variety of cell types including endothelial cells and smooth muscle cells. Therefore, the origin of the increased plasma OPG levels in diabetic subjects with microvascular disease is uncertain. We have previously shown that macular edema reflects widespread endothelial damage in patients with DMa (11). In the present study, we also found a strong correlation between the presence of DMa and incipient diabetic nephropathy. Thus, the elevated OPG levels in patients with maculopathy in this study may well represent an increased production of this molecule by endothelial cells and smooth muscle cells in diseased microvessels not only in the retina but in the entire microcirculation of these patients.

In consistency with previously published data $(3,8)$, we found a positive correlation between age and plasma OPG. In the present study, we tried to eliminate potential confounding by age and duration of diabetes by closely matching these parameters in the individuals from each group. In the previously mentioned paper (3), describing increased levels of OPG among patients with diabetes, a positive correlation between plasma levels of OPG and fructosamine was found. Our results are in line with these findings, as we were able to demonstrate a strong correlation between plasma OPG and $\mathrm{HbA}_{1 \mathrm{c}}$ in diabetic patients. This correlation may be confounded by underlying differences in the degree of vascular dysfunction, as we found increased values of both OPG and $\mathrm{HbA}_{1 \mathrm{c}}$ among diabetic patients with maculopathy. Further studies are clearly needed to clarify the causative relation between OPG, glycemia, and vascular damage.

In conclusion, we found increased levels of OPG in plasma from diabetic patients with microvascular complications. This finding supports the growing concept that OPG acts as an important regulatory molecule in the vasculature and, particularly, that it may be involved in the development of vascular dysfunction in diabetes. Larger, prospective studies are needed in order to further evaluate the associations between OPG and diabetic microvascular disease.

\section{Acknowledgements}

The Sehested Hansen Foundation, the Novo Nordisk Foundation, the Beckett Foundation, the Jochum Jensen Memorial Grant, Murermester Laurits Peter Christensen og hustru Kirsten Sigrid Christensens Fond, Helga og Peter Kornings Fond, the Illum Foundation, and the Danish Heart Foundation are acknowledged for financial support. The authors thank Merete Møller, Hanne Petersen, Lisbet Vester, Helle Hedegaard, and Anne Lone Larsen for their invaluable technical assistance.

\section{References}

1 Simonet WS, Lacey DL, Dunstan CR, Kelley M, Chang MS, Luthy $\mathrm{R}$ et al. Osteoprotegerin: a novel secreted protein involved in the regulation of bone density. Cell 199789 309-319.

2 Hofbauer LC \& Schoppet M. Serum measurement of osteoprotegerin - clinical relevance and potential applications. European Journal of Endocrinology 2001145 681-683.

3 Browner WS, Lui LY \& Cummings SR. Associations of serum osteoprotegerin levels with diabetes, stroke, bone density, fractures, and mortality in elderly women. Journal of Clinical Endocrinology and Metabolism 2001 86 631-637.

4 Dhore CR, Cleutjens JP, Lutgens E, Cleutjens KB, Geusens PP, Kitslaar PJ et al. Differential expression of bone matrix regulatory proteins in human atherosclerotic plaques. Arteriosclerosis, Thrombosis, and Vascular Biology 200121 1998-2003.

5 Bucay N, Sarosi I, Dunstan CR, Morony S, Tarpley J, Capparelli C et al. Osteoprotegerin-deficient mice develop early onset osteoporosis and arterial calcification. Genes and Development 1998 $121260-1268$.

6 Zhang J, Fu M, Myles D, Zhu X, Du J, Cao X et al. PDGF induces osteoprotegerin expression in vascular smooth muscle cells by multiple signal pathways. FEBS Letters 2002521 180-184.

7 Malyankar UM, Scatena M, Suchland KL, Yun TJ, Clark EA \& Giachelli CM. Osteoprotegerin is an alpha vbeta 3-induced, NF-kappa B-dependent survival factor for endothelial cells. Journal of Biological Chemistry $200027520959-20962$.

8 Jono S, Ikari Y, Shioi A, Mori K, Miki T, Hara K et al. Serum osteoprotegerin levels are associated with the presence and severity of coronary artery disease. Circulation 2002106 1192-1194.

9 Knudsen ST, Foss CH, Poulsen PL, Bek T, Ledet T, Mogensen CE et al. E-selectin-inducing activity in plasma from type 2 diabetic patients with maculopathy. American Journal of Physiology Endocrinology and Metabolism 2003284 E1-E6.

10 Hofbauer LC \& Schoppet M. Osteoprotegerin: a link between osteoporosis and arterial calcification? Lancet $2001358257-259$.

11 Knudsen ST, Bek T, Poulsen PL, Hove MN, Rehling M \& Mogensen CE. Macular edema reflects generalized vascular hyperpermeability in type 2 diabetic patients with retinopathy. Diabetes Care 200225 2328-2334.

Received 28 February 2003

Accepted 14 April 2003 